council. It was announced that the first volume of Prof. F. Balfour-Browne's "British Water Beetles" would shortly be issued to subscribers for 1939. The council, in its annual report, referred to the difficulties with which the Society is faced as a result of the War. The report continues : "The Council believe, however, that the work of the Society ought to be carried on as far as it is possible to do so in war time. In common with other scientific bodies, the Society has a definite function to perform in helping to maintain the continuity of our national life, of which its activities are a very small, but, as the Council believe, not a wholly negligible part. It is proposed therefore to go on with the publication of the works now being prepared, and the Council appeals to all members who are able to do so to continue their support of the Society."

\section{Association of Scientific Workers: New Branch}

THE recently formed Glasgow branch of the Association of Scientific Workers held its inaugural meeting in the Royal Technical College, Glasgow, on March 6. The proceedings opened with a display of films portraying the history of the vitamins and developments in the use of the cathode ray oscillograph. Dr. J. D. Sutherland, chairman of the branch, referred briefly to the aims and work of the Association and then called upon Prof. W. F. K. Wynne-Jones to deliver the inaugural address. Prof. Wynne-Jones led up to the general question of the organization of science and scientific workers by considering the planning of research. He said he is strongly opposed to the view that research should not be organized, and expressed the opinion that valuable results will only be obtained from an investigation if it is carefully planned beforehand. $\mathrm{He}$ contended that scientific research arises fundamentally from the needs of society, and illustrated his point with several very pertinent examples from the history of science. In furtherance of his argument for increased organization among scientific workers, Prof. Wynne-Jones spoke of the poor financial support received by research in Great Britain and of the muddles that had arisen at the outset of the War because men of science had not been called upon to organize services which belonged essentially to their province. Science can and must be organized, and to this end scientific workers must develop a corporate sense.

\section{Rhodes Scholarships for India}

THE Rhodes Trustees have decided to found two Rhodes Scholarships annually for India. The Rhodes Scholarships are of the annual value of $£ 400$, and tenable at the University of Oxford. With one or two exceptions they are awarded to young men who have been educated at universities in the British Dominions or in the United States of America. Cecil Rhodes laid down in his will that in the election of a scholar special regard should be paid to his scholastic attainments, his fondness for manly outdoor sports, his qualities of manhood, truth, courage, devotion to duty, unselfishness and sympathy for the weak, and his powers of leadership. The Rhodes Trustees are confident that candidates fully up to the high standard set by previous Rhodes Scholars will be forthcoming from India, and they have been assured that Indian Rhodes Scholars will be welcome at Oxford. These scholarships are founded for an initial period of five years, after which they will be reviewed in the light of experience. The first Indian Rhodes Scholars will go into residence at Oxford after the end of the War. This is the second announcement of post-graduate awards for Indian students which have been made in recent years; it will be recalled that the Commissioners of the Exhibition of 1851 instituted exhibitions for India in 1937.

\section{The Conception of the Atomic Clock}

The presidential address to the Section of Physies of the American Association for the Advancement of Science, which was delivered at Columbus on December 29 by Dr. Herbert E. Ives, is printed in Science $(91,79 ; 1940)$. The address is entitled "The Measurement of Velocity with Atomic Clocks". Taking the variation of atomic clock rate as an experimental fact, established by the Doppler effect in hydrogen canal rays, and adopting also the Fitzgerald contraction of moving rods indicated by the MichelsonMorley experiment, Dr. Ives points out that it is possible to define 'velocity' in various ways, none of which has any a priori claim to be chosen as 'correct'. The Restricted Theory of Relativity corresponds to the choice of one of them. "They are all deviations from the simple Newtonian concept of velocity", says Dr. Ives, "which is in terms of rods and clocks which are unaffected by motion. I urge the merit of the Newtonian framework as the only unambiguous basis for the idea of velocity". Dr. Ives does not consider that the ether has been "abolished" simply because it is possible to define velocity in a manner which makes it unnecessary to refer to that medium : he claims that the Sagnac experiment, in which beams of light moving in opposite directions round a rotating disk produce movable interference fringes, gives experimental evidence of the existence of the ether. His views, he says, "will be recognised as those of the earlier students of the subject-Fitzgerald, Larmor, Lorentz-but not of those who would shift the burden from variant measuring instruments to the nature of space and time".

Relativists will probably not be convinced by Dr. Ives's arguments. They will ask why, if there are invariant measuring rods and clocks, we cannot discover them but have to use those which vary with motion ; and further, why, of varying ones, we cannot tell in what state they approximate most closely to those which are immutable. It is to be noted also that Dr. Ives's address scarcely justifies the choice of title. An atom may be conceived as a clock, but cannot possibly be used as an instrument for measuring time or velocity unless we make an ad hoc definition of velocity in terms of wave-length changes and define an atom as a light-wave. 